\title{
Suitability of otolith microchemistry for stock separation of Baltic cod
}

\author{
F. Heidemann ${ }^{1, *}$, L. Marohn ${ }^{1,5}$, H. H. Hinrichsen ${ }^{1}$, B. Huwer ${ }^{2}$, K. Hüssy ${ }^{2}$, A. Klügel ${ }^{3}$, \\ U. Böttcher ${ }^{4}$, R. Hanel ${ }^{5}$ \\ ${ }^{1}$ Helmholtz Centre for Ocean Research Kiel, GEOMAR, Kiel 24105, Germany \\ ${ }^{2}$ National Institute of Aquatic Resources, Technical University of Denmark, Charlottenlund Castle, Charlottenlund 2920, \\ Denmark \\ ${ }^{3}$ Universität Bremen, Fachbereich Geowissenschaften, Bremen 28334, Germany \\ ${ }^{4}$ von Thünen-Institut (vTI) — Institute of Baltic Sea Fisheries, Rostock 18069, Germany \\ ${ }^{5}$ von Thünen-Institut (vTI) — Institute of Fisheries Ecology, Hamburg 22767, Germany
}

\begin{abstract}
Microchemical otolith analyses have been shown to provide valuable information on the life history, dispersal and stock characteristics of teleost fish. In the present study, the suitability of this technique for identifying the origin and distribution of Atlantic cod Gadus morhua L. from the Baltic Sea was examined using laser ablation-ICPMS. The capacity to distinguish individuals from different Baltic Sea stocks and from the adjacent North Sea stock based on incoporation of stock-specific elemental fingerprints along otolith growth axes was investigated. It was further tested if different origins led to spawning-site specific element concentrations in otolith cores. The results indicate that microchemical analyses of Baltic cod otoliths are applicable for differentiating individuals of different stocks. Analyses of similarities including 12 element/calcium ratios resulted in significant differences between individuals from the eastern and the western Baltic Sea and between North Sea and Baltic Sea samples. Sr/Ca, Ba/Ca, $\mathrm{Y} / \mathrm{Ca}, \mathrm{Mg} / \mathrm{Ca}, \mathrm{Zr} / \mathrm{Ca}$ and $\mathrm{Mn} / \mathrm{Ca}$ ratios had the strongest discriminatory power. A further separation of individuals caught in 3 different spawning grounds of the eastern Baltic, however, was not possible. Elemental compositions from the core regions of otoliths from young of the year cod caught in eastern and western Baltic Sea spawning grounds showed significant differences in $\mathrm{Sr} / \mathrm{Ca}, \mathrm{Ba} / \mathrm{Ca}$ and $\mathrm{Mg} / \mathrm{Ca}$ concentrations. Analyses of similarities again showed significant differences between these areas for juveniles. This study demonstrates the potential of otolith microchemical analyses to provide important information about the stock structure and connectivity of G. morhua in the Baltic Sea.
\end{abstract}

KEY WORDS: Gadus morhua $\cdot$ Stock discrimination $\cdot$ Baltic Sea $\cdot$ Otolith microchemistry

\section{INTRODUCTION}

The Atlantic cod Gadus morhua is distributed over vast areas of the northern Atlantic, including the North Sea and almost the entire Baltic Sea. Since the Baltic Sea is a brackish water system, Baltic cod face a range in salinity from fully marine levels in the northern Kattegat to almost freshwater conditions in the north-eastern inner parts of the Baltic Sea. Genotypic and phenotypic characteristics indicate a separation into a western (International Council for the Exploration of the Sea [ICES] subdivisions SD 22-24) and an eastern Baltic cod stock (SD 25-32). The separation into 2 Baltic cod stocks is made for management reasons based on the assumption that these stocks are spatially separated. However, overlapping 
between the stocks has been reported in a relatively narrow zone around the island of Bornholm (Bagge et al. 1994, Nielsen et al. 2003).

Both Baltic stocks are subject to large fluctuations in spawning stock biomass and recruitment (Eero et al. 2011, Hüssy 2011). Besides the influence of fisheries, the eastern Baltic stock dynamics are mainly driven by changes in salinity and oxygen (Köster et al. 2005). This is particularly due to a special set of environmental conditions required for successful reproduction in the eastern parts of the Baltic Sea (MacKenzie et al. 2000). Historically, there have been 3 main spawning areas for the eastern Baltic stock: the Bornholm Basin (BB), the Gdansk Deep (GD) and the Gotland Basin (GB). Analyses of the spatial and temporal heterogeneity of the spawning environment have revealed that beneficial conditions for egg survival are most likely to be found in the BB (MacKenzie et al. 2000). Due to a lack of oxygen combined with low salinities, the more eastern spawning grounds in the GD and GB do not often provide adequate environmental conditions for egg survival, especially since the early 1980s (Nissling et al. 1994, Köster et al. 2005). For the western Baltic cod, the number of potential spawning grounds is less limited, and good spawning conditions are found in several areas from the Kattegat to the Arkona Basin (Hüssy 2011).

The degree of connectivity between the 2 Baltic cod stocks is still under debate. In the Baltic Sea, Gadus morhua is distributed over a large area and may perform wide and variable feeding and spawning migrations through different environments (Otterlind 1985). The younger age groups are usually found in coastal areas (Bagge \& Steffensen 1989), while horizontal movements of adult individuals in the distribution area were found to not be clearly directed and were therefore described as random migrations (Bagge et al. 1974). In the transition zone between the eastern and the western stocks, some exchange may occur. Tagging studies revealed that individuals from the Arkona Basin can undertake long eastward migrations (Otterlind 1985), and genetic studies suggest that even interbreeding between both stocks occurs in that area (Nielsen et al. 2003). However, the extent that migrations and interbreeding contribute to the mixing between stocks remains to be quantified. Successful management of Baltic cod stocks requires knowledge about the connectivity among stocks within the Baltic Sea as well as between the North Sea and the western Baltic Sea. Furthermore, identification of the natal origins of individuals would allow quantification of the contribution of each spawning ground to the spawning stock biomass and therefore significantly improve the understanding of stock dynamics.

Among other uses, otolith microchemistry analysis provides a promising tool for fish stock discrimination, as shown for pink snapper Chrysophrys auratus (Edmonds et al. 1989), orange roughy Hoplostethus atlanticus (Edmonds et al. 1991), jackass morwong Nemadactylus macropterus (Thresher et al. 1994), Spanish mackerels Scomberomorus spp. (Begg et al. 1998) and Atlantic cod (Campana et al. 2000, Higgins et al. 2010, Limburg et al. 2010, Svedäng et al. 2010). In these studies, several elements in otoliths differed among sampling sites. Svedäng et al. (2010) even found better distinction among populations by otolith chemistry than by genetic investigation. In most of the studies on fish otoliths, $\mathrm{Mg}$ or $\mathrm{Na}$ had the highest discrimination potential, but the results from different fish species are not consistent. For Atlantic cod, particularly Mg, $\mathrm{Mn}, \mathrm{Ba}$ and $\mathrm{Sr}$ as well as Rb (Higgins et al. 2010) and $\mathrm{Br}$ (Limburg et al. 2010) could distinguish among populations. The differing element levels in otoliths can be explained either by individual physiology constraints (Kalish 1989), ambient environmental conditions, like temperature and salinity (Fowler et al. 1995), or a combination of both, but genetic or ontogenetic influences are also discussed (Thresher et al. 1994, Begg et al. 1998).

It seems promising that the east-west salinity gradient within the Baltic Sea and the strong regional influence of river discharge on the water composition (e.g. Andersson et al. 1992, Maksymowska et al. 2000, Wachniew 2006) provide appropriate conditions for a discrimination of spawning-site specific elemental fingerprints in the otoliths of discrete Baltic cod stocks. The objective of the present study was to assess the potential of otolith microchemistry to differentiate between the cod stocks through comparative analyses of the multi-elemental composition of otoliths of adult specimens caught in the North Sea (NS), the western Baltic Sea (WB) as well as the 3 eastern Baltic spawning grounds BB, GD and GB using laser ablation inductively coupled plasma mass spectrometry (LAICPMS). In addition, it was tested whether individuals of different origins are characterized by distinguishable elemental compositions in the core regions of their otoliths. Therefore, multi-element analyses were conducted in the core area of juvenile cod otoliths from the eastern and the western Baltic Sea. 


\section{MATERIALS AND METHODS}

\section{Sample material and preparation}

Adult Atlantic cod Gadus morhua were caught in winter to spring of 1998 during the spawning season in the Baltic and North Sea (Fig. 1, Table 1). Juveniles were collected later in the same year from WB and BB (Fig. 1). A total of 89 sagittal otoliths were removed from adult Atlantic cod and 20 sagittal otoliths from juvenile specimens (Table 1). All otoliths collected were stored in paper bags until preparation.

Adult cod otoliths were embedded in a mixture of GTS polyester casting resin and MEKP-hardener (both from Voss Chemie) and thin-sectioned across the center of the otolith using a semi-automated mineralogy sawing machine (Conrad). These cross sections as well as the juvenile otoliths were mounted on glass slides with thermoplastic glue (Crystalbond Type 509; Kager) and subsequently polished with lapping film (30, 12 and $3 \mu \mathrm{m} ; 3 \mathrm{M})$.

\section{Otolith analyses}

Concentrations of trace elements were determined by LA-ICPMS using a NewWave UP193 solid-state laser coupled to a ThermoFinnigan Element2 ${ }^{\mathrm{TM}}$ at the Department of Geosciences, University of Bremen. Elemental composition of adult cod otoliths was measured along transects from the core to the dorsal edge of the otolith sections (Fig. 2). Otoliths were ablated with an irradiance of ca. $1 \mathrm{GW} \mathrm{cm}^{-2}$, a pulse rate of $10 \mathrm{~Hz}$, a spot size of $75 \mu \mathrm{m}$ and a line scan speed of $4 \mu \mathrm{m} \mathrm{s}^{-1}$. Sixteen isotopes $\left({ }^{7} \mathrm{Li},{ }^{23} \mathrm{Na}^{25} \mathrm{Mg}\right.$, ${ }^{43} \mathrm{Ca},{ }^{55} \mathrm{Mn},{ }^{65} \mathrm{Cu},{ }^{66} \mathrm{Zn},{ }^{85} \mathrm{Rb},{ }^{88} \mathrm{Sr},{ }^{89} \mathrm{Y},{ }^{90} \mathrm{Zr},{ }^{93} \mathrm{Nb}$, ${ }^{111} \mathrm{Cd},{ }^{138} \mathrm{Ba},{ }^{208} \mathrm{~Pb}$ and ${ }^{238} \mathrm{U}$ ) were analyzed. Element/ calcium $(\mathrm{El} / \mathrm{Ca})$ ratios were averaged over the entire measuring transects for every element. Otoliths of juveniles were ablated as single points in the core region for $60 \mathrm{~s}$ with a pulse rate of $5 \mathrm{~Hz}$ and a spot size of $50 \mu \mathrm{m}$, producing shallow $(<25 \mu \mathrm{m})$ craters. Mean El/Ca ratios were determined for every juvenile specimen, measuring the same 16 elements as for transect analyses. A pre-ablation was carried out prior to every measurement in order to clean the

Table 1. Gadus morhua sampling data. NS: North Sea, WB: Western Baltic, BB: Bornholm Basin, GD: Gdansk Deep, GB: Gotland Basin, SD: ICES Subdivision, N: number of fish, TL: total length

\begin{tabular}{|lcrcc|}
\hline \multirow{2}{*}{ Region } & \multirow{2}{*}{ Catch date } & \multirow{N}{*}{ N } & \multicolumn{2}{c|}{ TL (cm) } \\
\cline { 4 - 5 } & & & Range & Mean \\
\hline Adults & & & & \\
NS & Feb 1998 & 16 & $30-49$ & 35.7 \\
WB & Jan-Mar 1998 & 19 & $51-60$ & 55 \\
BB & May 1998 & 24 & $46-76$ & 53 \\
GD & May 1998 & 9 & $50-61$ & 54.2 \\
GB & May 1998 & 21 & $48-67$ & 56 \\
Juveniles & & & & \\
SD22 (WB) & Jun 98 & 11 & $2.6-4.4$ & 3.5 \\
SD25 (BB) & Nov 98 & 9 & $3.4-4.5$ & 3.8 \\
\hline
\end{tabular}

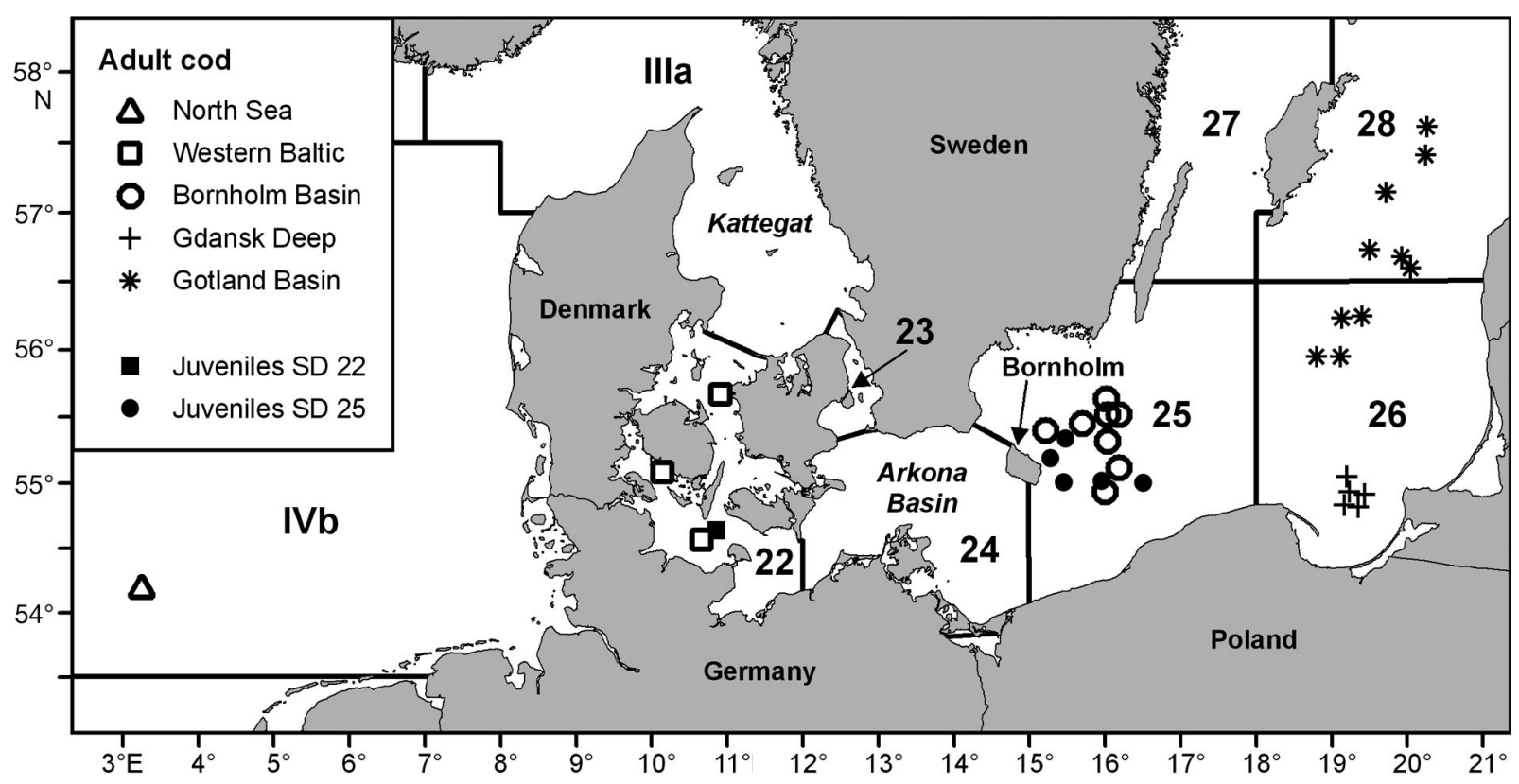

Fig. 1. Sampling areas of Atlantic cod Gadus morhua. Numbers represent ICES subdivisions (SD) 


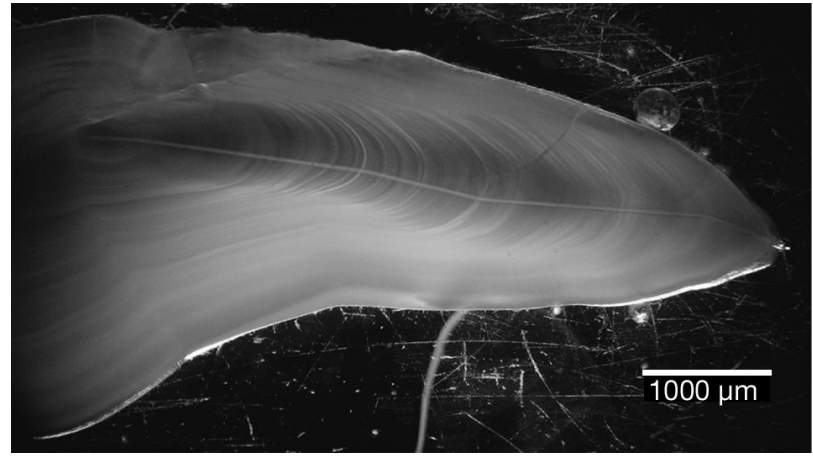

Fig. 2. Ablation line after LA-ICPMS measurements along the growth axis of an adult cod otolith

surface. Helium was used $\left(0.41 \mathrm{~min}^{-1}\right)$ as sample gas and argon $\left(0.8 \mathrm{l} \mathrm{min}^{-1}\right)$ as make-up gas. Plasma power was $1200 \mathrm{~W}$. Isotopes were analyzed at low resolution with 5 samples in a $20 \%$ mass window and a total dwell time of $50 \mathrm{~ms}$ per isotope. Blanks were measured for $20 \mathrm{~s}$ prior to ablation.

For external calibration, the NIST612 standard reference material, a sodium silicate glass, was analyzed after each transect (standard bracketing). Calcium was used as an internal standard with an assumed concentration of $38.8 \mathrm{wt} \%$ for the otoliths (similar to the NIES22 otolith material; Yoshinaga et al. 2000). For data quantification, the Cetac GeoPro ${ }^{\mathrm{TM}}$ software was used with the concentrations for NIST612 of Pearce et al. (1997). The Mg concentration provided by these authors $\left(77.4 \mathrm{\mu g} \mathrm{g}^{-1}\right)$, however, significantly differed from the newly determined value of $68 \mu^{-1} \mathrm{~g}^{-1}$ (Jochum et al. 2011).

The data quality was assessed by repeated analyses of a pressed pellet of NIES22 otolith powder (Table 2) and of BCR2G basaltic glass (United States Geological Survey). For $\mathrm{Na}, \mathrm{Mg}, \mathrm{Cu}, \mathrm{Zn}, \mathrm{Sr}$ and $\mathrm{Ba}$, there is good to excellent agreement with the certi-

Table 2. Average concentration and relative standard deviation (RSD) of 9 analyses of a pressed pellet from NIES22 otolith powder. The $\mathrm{Mg}$ concentration in parentheses is based on the calibration value from Jochum et al. (2011)

\begin{tabular}{|lccc|}
\hline Element & $\begin{array}{c}\text { Concentration } \\
\left(\mu \mathrm{g} \mathrm{g}^{-1}\right)\end{array}$ & $\begin{array}{c}\text { RSD } \\
(\%)\end{array}$ & $\begin{array}{c}\text { Reference } \\
\text { value }\left(\mu \mathrm{g} \mathrm{g}^{-1}\right)\end{array}$ \\
\hline $\mathrm{Na}$ & 2270 & 5.1 & 2230 \\
$\mathrm{Mg}$ & $25.8(22.7)$ & 14 & 21 \\
$\mathrm{Cu}$ & 0.796 & 30 & 0.74 \\
$\mathrm{Zn}$ & 0.531 & 23 & 0.47 \\
$\mathrm{Sr}$ & 2302 & 2.8 & 2360 \\
$\mathrm{Ba}$ & 2.7 & 2.6 & 2.89 \\
$\mathrm{~Pb}$ & 0.042 & 46 & 0.023 \\
\hline
\end{tabular}

fied values, which indicates that NIST612 is well suited as a calibration standard for carbonate analyses. The accuracy for Mg improves significantly if the Jochum et al. (2011) value rather than the Pearce et al. (1997) value for NIST612 is used for calibration. Because the variations of our NIES22 analyses include heterogeneities within the pellet, the actual analytical precision of the laboratory setup is better than the relative standard deviations shown in Table 2; based on our BCR2G data, the overall precision is better than $5 \%$ for most elements at concentrations above 0.5 to $1 \mathrm{\mu g} \mathrm{g}^{-1}$.

\section{Statistical analysis}

Statistical evaluation was conducted using the software STATISTICA (Version 6.1, StatSoft 2003) and PRIMER 6 (Version 6.1.9, PRIMER-E) (Clarke \& Gorley 2001).

For statistical analysis, transect data for each adult cod otolith were averaged for single elements. Means were grouped according to the sampling region (NS, $\mathrm{WB}, \mathrm{BB}, \mathrm{GD}$ or GB) and tested in univariate analyses of variance (ANOVA) for each element. In order to assign differences among sampling regions, ANOVA was followed by Tukey's honestly significant difference (HSD) multiple comparison test. Where variances were not distributed homogeneously among factor levels, a Kruskal-Wallis $H$ test was performed. The ANOVA and Kruskal-Wallis $H$ test were conducted using a Bonferroni corrected level of significance $(p=0.004)$.

The combination of transect means of all analyzed elements forms an elemental fingerprint of the otolith of the respective individual. To test if these elemental fingerprints differ significantly among sampling areas, 4th-root transformed data were used to perform an analysis of similarities (ANO$\mathrm{SIM}_{\text {; }}$ significance level $\mathrm{p}=0.05$ ). In addition, a discriminant analysis was conducted using the transformed data to evaluate the contribution of single elements to the differentiation among sampling areas (significance level $\mathrm{p}=0.05$ ). For graphical representation, a non-metric multidimensional scaling (MDS) plot was created on the basis of a BrayCurtis-similarity matrix.

Differences of element concentrations of juvenile cod from the western and eastern Baltic Sea were analyzed using $t$-tests (Bonferroni corrected level of significance $p=0.004$ ). Differences in otolith elemental fingerprints of juveniles were visualized using an MDS plot. 


\section{RESULTS}

\section{Elemental fingerprints of adult cod}

An overview of the mean values of measured otolith El/Ca ratios for each sampling area is presented in Table 3. The elements $\mathrm{Cd}, \mathrm{Nb}$ and $\mathrm{U}$ were excluded from statistical evaluation because their concentrations were close to the detection limits.

Highly significant differences between the sampling areas were found for all 12 remaining elements (Table 4). Individual elemental fingerprints including the 12 elements ( $\mathrm{Li}, \mathrm{Na}, \mathrm{Mg}, \mathrm{Mn}, \mathrm{Cu}, \mathrm{Zn}, \mathrm{Rb}, \mathrm{Sr}, \mathrm{Y}$, $\mathrm{Zr}, \mathrm{Ba}$ and $\mathrm{Pb}$ ) are visualized by the MDS plot in Fig. 3. Samples from the North Sea (NS) are isolated from all other samples, and the Western Baltic (WB)

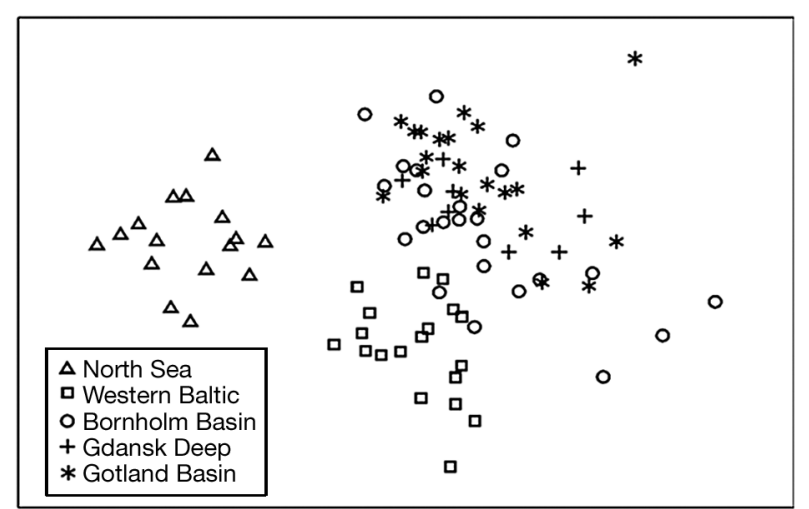

Fig. 3. Multidimensional scaling plot of otolith elemental fingerprints of adult Atlantic cod. Each data point represents one elemental fingerprint, including 12 element/calcium ratios of the respective otolith

Table 3. Mean ( \pm SD) element/calcium ratios of adult Atlantic cod otoliths for different sampling areas. NS: North Sea, WB: Western Baltic, BB: Bornholm Basin, GD: Gdansk Deep, GB: Gotland Basin

\begin{tabular}{|c|c|c|c|c|c|}
\hline & NS & WB & BB & GD & GB \\
\hline $\mathrm{Li} / \mathrm{Ca}\left(\mu \mathrm{mol} \mathrm{mol}^{-1}\right)$ & $8.40( \pm 5.00)$ & $2.57( \pm 0.97)$ & $1.31( \pm 0.88)$ & $1.50( \pm 0.52)$ & $1.67( \pm 0.84)$ \\
\hline $\mathrm{Na} / \mathrm{Ca}\left(\mathrm{mmol} \mathrm{mol}{ }^{-1}\right)$ & $16.98( \pm 0.58)$ & $17.44( \pm 1.01)$ & $16.52( \pm 0.75)$ & $16.10( \pm 0.44)$ & $16.13( \pm 0.67)$ \\
\hline $\mathrm{Mg} / \mathrm{Ca}\left(\mu \mathrm{mol} \mathrm{mol}{ }^{-1}\right)$ & $161.89( \pm 22.40)$ & $130.53( \pm 13.62)$ & $129.34( \pm 21.45)$ & $129.28( \pm 16.01)$ & $123.35( \pm 14.65)$ \\
\hline $\mathrm{Mn} / \mathrm{Ca}\left(\mu \mathrm{mol} \mathrm{mol}{ }^{-1}\right)$ & $13.65( \pm 7.89)$ & $37.56( \pm 22.52)$ & $24.00( \pm 7.94)$ & $21.37( \pm 6.45)$ & $27.10( \pm 12.75)$ \\
\hline $\mathrm{Cu} / \mathrm{Ca}\left(\mu \mathrm{mol} \mathrm{mol}{ }^{-1}\right)$ & $0.53( \pm 0.20)$ & $2.19( \pm 0.81)$ & $1.48( \pm 1.27)$ & $1.99( \pm 1.36)$ & $0.88( \pm 0.60)$ \\
\hline $\mathrm{Zn} / \mathrm{Ca}\left(\mu \mathrm{mol} \mathrm{mol}{ }^{-1}\right)$ & $1.21( \pm 0.30)$ & $2.72( \pm 0.91)$ & $2.00( \pm 0.97)$ & $2.01( \pm 0.78)$ & $1.41( \pm 0.61)$ \\
\hline $\mathrm{Rb} / \mathrm{Ca}\left(\mu \mathrm{mol} \mathrm{mol}{ }^{-1}\right)$ & $0.23( \pm 0.03)$ & $0.41( \pm 0.08)$ & $0.34( \pm 0.12)$ & $0.44( \pm 0.15)$ & $0.29( \pm 0.07)$ \\
\hline $\mathrm{Sr} / \mathrm{Ca}\left(\mathrm{mmol} \mathrm{mol}^{-1}\right)$ & $2.38( \pm 0.28)$ & $2.18( \pm 0.22)$ & $1.70( \pm 0.21)$ & $1.54( \pm 0.11)$ & $1.45( \pm 0.14)$ \\
\hline $\mathrm{Y} / \mathrm{Ca}\left(\mathrm{nmol} \mathrm{mol}^{-1}\right)$ & $29.41( \pm 3.74)$ & $20.64( \pm 2.47)$ & $16.98( \pm 3.52)$ & $20.47( \pm 1.70)$ & $18.43( \pm 1.93)$ \\
\hline $\mathrm{Zr} / \mathrm{Ca}\left(\mathrm{nmol} \mathrm{mol}{ }^{-1}\right)$ & $15.93( \pm 6.70)$ & $42.23( \pm 29.01)$ & $112.94( \pm 96.60)$ & $59.20( \pm 88.55)$ & $95.06( \pm 88.79)$ \\
\hline $\mathrm{Nb} / \mathrm{Ca}\left(\mathrm{nmol} \mathrm{mol}^{-1}\right)$ & $2.40( \pm 0.47)$ & $0.50( \pm 0.96)$ & $0.22( \pm 0.84)$ & $1.43( \pm 0.29)$ & $0.70( \pm 0.66)$ \\
\hline $\mathrm{Cd} / \mathrm{Ca}\left(\mathrm{nmol} \mathrm{mol}^{-1}\right)$ & $13.29( \pm 12.15)$ & $14.73( \pm 14.70)$ & $20.73( \pm 18.52)$ & $21.07( \pm 21.43)$ & $19.43( \pm 11.22)$ \\
\hline $\mathrm{Ba} / \mathrm{Ca}\left(\mu \mathrm{mol} \mathrm{mol}{ }^{-1}\right)$ & $2.21( \pm 0.60)$ & $4.88( \pm 1.14)$ & $6.80( \pm 1.56)$ & $6.70( \pm 1.67)$ & $6.60( \pm 1.16)$ \\
\hline $\mathrm{Pb} / \mathrm{Ca}\left(\mathrm{nmol} \mathrm{mol}{ }^{-1}\right)$ & $6.43( \pm 3.46)$ & $46.20( \pm 30.57)$ & $36.34( \pm 29.77)$ & $24.42( \pm 17.14)$ & $22.12( \pm 17.93)$ \\
\hline $\mathrm{U} / \mathrm{Ca}\left(\mathrm{nmol} \mathrm{mol}{ }^{-1}\right)$ & $0.22( \pm 0.24)$ & $0.10( \pm 0.04)$ & $-0.01( \pm 0.25)$ & $0.08( \pm 0.07)$ & $0.07( \pm 0.02)$ \\
\hline
\end{tabular}

Table 4. Results of analysis of variance (ANOVA, F-test) and Kruskal-Wallis $H$-test, summary of discriminant analysis in otoliths of adult Atlantic cod among sampling areas and results of $t$-tests for element/calcium ratios in the core region of juvenile cod otoliths

\begin{tabular}{|c|c|c|c|c|c|c|c|c|c|}
\hline & \multicolumn{4}{|c|}{ - ANOVA \& Kruskal-Wallis $H$-test - } & \multicolumn{2}{|c|}{ Discriminant analysis } & \multirow{2}{*}{\multicolumn{2}{|c|}{$\begin{array}{c}-t \text {-test juvenile cod } \\
t \text {-value }\end{array}$}} & \multirow{2}{*}{$d-$} \\
\hline & $F$ & $H$ & $\mathrm{p}$ & df & $F$ & $\mathrm{p}$ & & & \\
\hline $\mathrm{Sr} / \mathrm{Ca}$ & - & 66.61 & 0.000 & 4 & 40.09 & 0.000 & $\mathrm{Sr} / \mathrm{Ca}$ & 3.60 & 0.002 \\
\hline $\mathrm{Ba} / \mathrm{Ca}$ & - & 52.69 & 0.000 & 4 & 27.66 & 0.000 & $\mathrm{Ba} / \mathrm{Ca}$ & -4.49 & 0.000 \\
\hline $\mathrm{Y} / \mathrm{Ca}$ & - & 51.78 & 0.000 & 4 & 14.86 & 0.000 & $\mathrm{Y} / \mathrm{Ca}$ & 1.98 & 0.063 \\
\hline $\mathrm{Mg} / \mathrm{Ca}$ & 11.92 & - & 0.000 & 4 & 6.98 & 0.000 & $\mathrm{Mg} / \mathrm{Ca}$ & 3.83 & 0.001 \\
\hline $\mathrm{Zr} / \mathrm{Ca}$ & - & 37.30 & 0.000 & 4 & 6.28 & 0.000 & $\mathrm{Zr} / \mathrm{Ca}$ & -0.77 & 0.452 \\
\hline $\mathrm{Mn} / \mathrm{Ca}$ & - & 32.14 & 0.000 & 4 & 5.66 & 0.001 & $\mathrm{Mn} / \mathrm{Ca}$ & 2.24 & 0.038 \\
\hline $\mathrm{Na} / \mathrm{Ca}$ & 9.94 & - & 0.000 & 4 & 4.09 & 0.005 & $\mathrm{Na} / \mathrm{Ca}$ & 2.22 & 0.039 \\
\hline $\mathrm{Rb} / \mathrm{Ca}$ & - & 41.72 & 0.000 & 4 & 2.16 & 0.082 & $\mathrm{Rb} / \mathrm{Ca}$ & 1.28 & 0.217 \\
\hline $\mathrm{Cu} / \mathrm{Ca}$ & - & 40.00 & 0.000 & 4 & 1.57 & 0.193 & $\mathrm{Cu} / \mathrm{Ca}$ & -1.36 & 0.192 \\
\hline $\mathrm{Li} / \mathrm{Ca}$ & - & 53.57 & 0.000 & 4 & 1.31 & 0.273 & $\mathrm{Li} / \mathrm{Ca}$ & -1.01 & 0.325 \\
\hline $\mathrm{Pb} / \mathrm{Ca}$ & - & 36.58 & 0.000 & 4 & 0.86 & 0.490 & $\mathrm{Cd} / \mathrm{Ca}$ & 1.81 & 0.088 \\
\hline $\mathrm{Zn} / \mathrm{Ca}$ & - & 31.65 & 0.000 & 4 & 0.34 & 0.851 & $\mathrm{Zn} / \mathrm{Ca}$ & -0.24 & 0.812 \\
\hline
\end{tabular}


samples are separated from the cluster of eastern Baltic samples (BB, GD and GB). Non-parametric ANOSIM revealed significant differences among sampling areas (global $\mathrm{R}=0.574, \mathrm{p}<0.001$ ). Pairwise a posteriori tests showed significant differences based on elemental composition between the NS and all other areas (Table 5) as well as between WB and the 3 different eastern Baltic areas. Within the eastern Baltic, only BB and GB differed significantly.

Discriminant analysis showed that $\mathrm{Sr}, \mathrm{Ba}, \mathrm{Y}, \mathrm{Mg}, \mathrm{Zr}$ and $\mathrm{Mn}$ had the strongest influence on the differentiation among the sampling areas (Table 4). Concentrations of these individual elements differed significantly between North Sea samples and most samples from the different Baltic Sea areas (Tukey's HSD multiple comparison test) (Fig. 4). Furthermore, Sr and $\mathrm{Ba}$ concentrations diverged between western and eastern Baltic samples, and $\mathrm{Sr}$ and Y differed between at least 2 of the 3 eastern Baltic areas.

\section{Elemental fingerprints of juvenile cod}

With respect to core concentrations of juvenile cod otoliths, $\mathrm{Pb}, \mathrm{Nb}$ and $\mathrm{U}$ fluctuated strongly around
Table 5. Results (R statistic) of pairwise tests of similarity analysis (ANOSIM). NS: North Sea, WB: Western Baltic, BB: Bornholm Basin, GD: Gdansk Deep, GB: Gotland Basin. ${ }^{* *} \mathrm{p} \leq 0.01 ;{ }^{* * *} \mathrm{p} \leq 0.001$

\begin{tabular}{|ccccc|}
\hline & NS & WB & BB & GD \\
\hline WB & $0.960^{* *}$ & - & - & - \\
BB & $0.881^{* *}$ & $0.453^{* * *}$ & - & - \\
GD & $0.985^{* * *}$ & $0.736^{* * *}$ & -0.036 & - \\
GB & $0.946^{* * *}$ & $0.781^{* * *}$ & $0.090^{* *}$ & 0.133 \\
\hline
\end{tabular}

zero. These 3 elements were therefore excluded from statistical analyses. Results of $t$-tests between otoliths from WB (SD 22) and those from BB (SD 25) are listed in Table 4 for each element. The core concentrations of juvenile cod otoliths differed significantly among sampling areas for $\mathrm{Sr}, \mathrm{Ba}$ and $\mathrm{Mg}$ (Table 4, Fig. 5). Other elements showed no significant differences when a Bonferroni corrected level of significance was applied. Elemental fingerprints of juvenile cod, including all $12 \mathrm{El} / \mathrm{Ca}$ ratios, were sufficient to distinguish samples according to their sampling areas ( $p=0.002$; Fig. 6$)$. Test statistics of a conducted ANOSIM were significant $(\mathrm{p}=0.002$, global $\mathrm{R}=0.506$ ) .
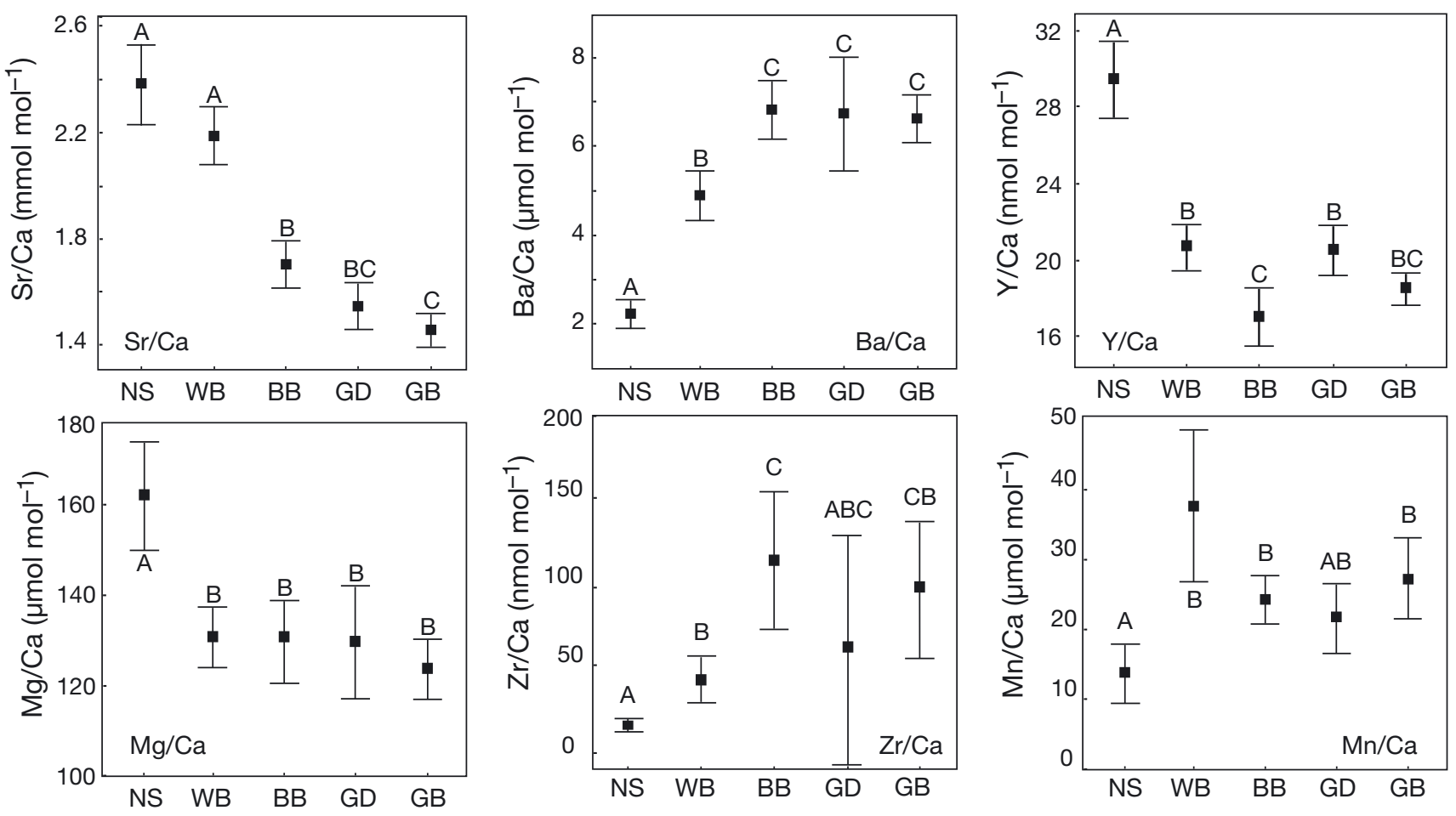

Fig. 4. Element/calcium ratios of elements with highest potential to distinguish among sampling areas of Atlantic cod. (घ) Overall mean values, error bars: $95 \%$ confidence interval. Groups without significant difference are labeled with the same letters. NS: North Sea, WB: Western Baltic, BB: Bornholm Basin, GD: Gdansk Deep, GB: Gotland Basin 

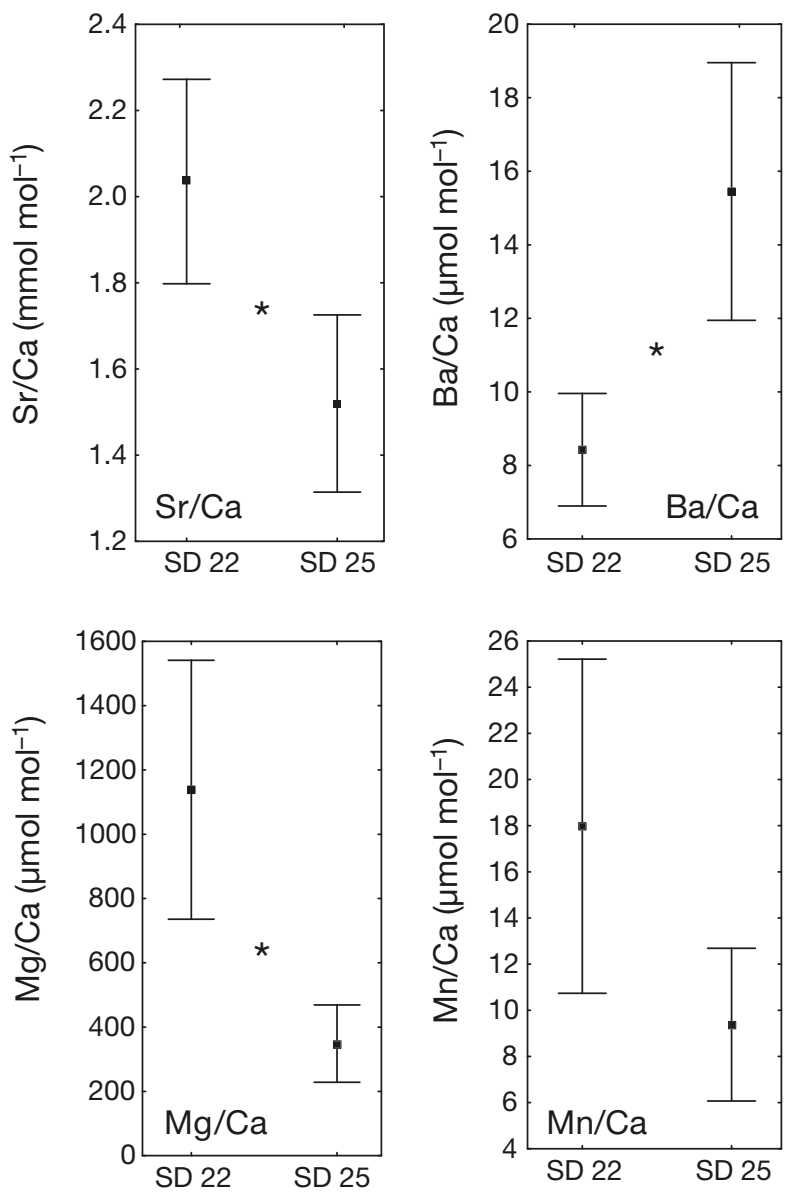

Fig. 5. Element/calcium ratios in core of juvenile cod otoliths for $\mathrm{Sr}, \mathrm{Ba}, \mathrm{Mg}$ and $\mathrm{Mn}$. (匹) Mean values. Error bars show the $95 \%$ confidence interval. ${ }^{*}$ Significant differences between the sampling areas based on $t$-tests. SD 22: Western Baltic, SD 25: Bornholm Basin

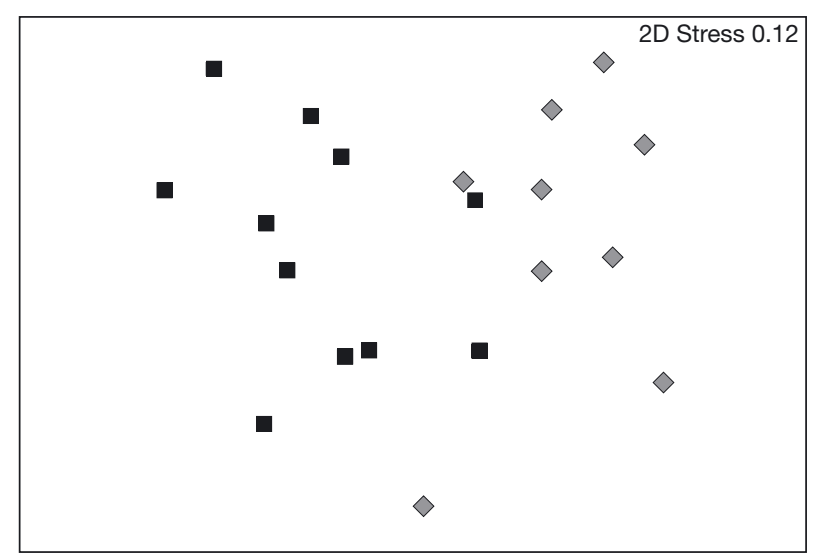

Fig. 6. Multidimensional scaling plot of elemental fingerprints in cores of juvenile cod otoliths, grouped according to sampling areas. $\mathbf{\square}$ : Western Baltic (SD 22), $\diamond$ : Bornholm Basin (SD 25)

\section{DISCUSSION}

The present study demonstrates that the unique hydrographic conditions of the Baltic Sea, which change over comparably short distances, provide suitable conditions for the use of otolith microchemistry as a potential discriminator of Baltic cod stocks. Water salinity ranges from almost fully marine in the Kattegat to almost freshwater in the innermost part of the Gulf of Bothnia, and the local influence of river discharge is strong (Andersson et al. 1992). It can be assumed that most of the discrimination among areas detected in the present study is caused by differences in water salinity, which was shown to be positively correlated with otolith $\mathrm{Sr} / \mathrm{Ca}$ ratios for several fish species (e.g. Secor et al. 1995, Secor \& Rooker 2000). However, the $\mathrm{Sr} / \mathrm{Ca}$ ratio alone does not explain the separation of Atlantic cod between the North Sea and the Western Baltic. Hence, consistent variations in additional elements are responsible for the significant differentiation of the 2 stocks. Besides $\mathrm{Sr}, \mathrm{Ba}$ incorporation is known to vary with water salinity (de Vries et al. 2005). In our results, Ba was the second strongest discriminator between sampling locations for adult Atlantic cod, with concentrations that increased eastwards inversely to water salinity. In juvenile cod, Ba had the largest effect on separation among sampling areas, supporting the assumption that water salinity has the main influence on the element incorporation into cod otoliths in the Baltic Sea.

Although differences in elements with high discriminatory power $(\mathrm{Sr}, \mathrm{Ba}, \mathrm{Y}, \mathrm{Mg}, \mathrm{Zr}$ and $\mathrm{Mn}$ ) were generally most pronounced between the North Sea and the Western Baltic, some elements ( $\mathrm{Sr}$ and $\mathrm{Ba}$ ) also differed between western and eastern Baltic samples. Beside these comparably highly concentrated elements, some heavy metals $(\mathrm{Zn}, \mathrm{Cu}, \mathrm{Pb}$ and Cd) also showed elevated concentrations in Baltic cod otoliths, potentially reflecting higher water concentrations caused by pollution (Pohl et al. 1999, BLMP 2002). Although values fluctuated largely among individuals from the same sampling areas, heavy metals might provide potential candidate elements in future studies. In contrast, Y concentrations remained very stable for each sampling area. Although Y could only be used to distinguish among sampling areas for adult cod and showed no differences between areas for juveniles, it seems promising to determine its discrimination potential in future studies.

The results support earlier studies that suggested a limited exchange of individuals between western 
and eastern Baltic Sea stocks. Morphometric and meristic analyses (e.g. Berner \& Vaske 1985, Müller 2002) as well as genetic studies (Nielsen et al. 2003) revealed a separation of the Baltic Sea cod into a western and an eastern stock. Mixing apparently only occurs to a limited extent and can be caused either by individual migration or by egg and larval drift. Our results concur with these findings and indicate that otolith microchemistry provides a powerful tool to further understand stock structure in the Baltic Sea, particularly because this method is moderately time-consuming and involves low costs compared to e.g. genetic methods, if the technology is available. Since adult Atlantic cod in this study were caught during the spawning season, differences in otolith element concentrations as detected among spawning areas indicate that spawning communities are separated for a considerable time of the year and suggest spawning site fidelity and a limited range of feeding migrations.

Despite the good discrimination potential of many of the elements analyzed, it was not possible to determine characteristic elemental fingerprints that clearly differ among the 3 eastern Baltic spawning grounds. Although Sr and Y contents differed significantly among $\mathrm{BB}, \mathrm{GD}$ and $\mathrm{GB}$, the combination of all analyzed elements did not lead to clear discriminating patterns. This might be caused by very similar water composition within the eastern Baltic Sea or by high connectivity among spawning areas, as reported for cod from GB that leave endemic spawning areas to migrate westward when spawning conditions suffer from a lack of oxygen or when cod densities in this area are high (Baranova 1989, 1995).

Our analysis revealed that otoliths of adult Atlantic cod individuals from different areas differed in their elemental composition, which may indicate that the exchange among stocks is limited. However, definite conclusions on the connectivity among stocks and spawning areas could not be drawn by this approach. The averaging of measurement data over the entire transect did not allow resolution of the elemental composition in the otolith core area, which corresponds to the early life stage and thus to the area where an individual was born, because an adequate exposure of the otolith core was precluded by the preparation of the entire otolith. Therefore, a second approach was necessary to evaluate the suitability of otolith microchemistry to assess the connectivity among Baltic Sea cod stocks. To address this question, core regions of young of the year cod from 2 spawning grounds in the Baltic Sea were analyzed. Statistically significant differences between juveniles originating from the western and the eastern Baltic stocks demonstrate the feasibility of chemical otolith tags to trace the individual origin of Baltic Sea cod. Our findings strengthen the assumption that core regions of Baltic cod otoliths store the specific hydrographic conditions of their respective natal origin. Presuming these conditions to be stable, site specific otolith core element concentrations could be used as markers for stock affiliation and deliver invaluable information on stock separation and stock connectivity. However, it has to be considered that water elemental composition may vary in time, and differences among regions might change among years (e.g. Gillanders \& Kingsford 2000). Campana et al. (2000) reported that long term stability of fingerprints for a certain spawning group was not given but that chemical signatures incorporated at a certain location are very stable for up to $1 \mathrm{yr}$. Whether this is true for the Baltic Sea or if conditions are stable over longer time periods has to be clarified in future studies.

In summary, elemental fingerprints of Atlantic cod otoliths are well suited to gain additional knowledge on the stock structure within the Baltic Sea. Even though the method is apparently not appropriate for the small-scale separation within the eastern Baltic cod stock, it can provide valuable information to improve stock management. The combination of biological markers with otolith microchemistry as done by Higgins et al. (2010) and the inclusion of water composition analyses could further improve the separation of Baltic cod stocks. Since the inter-relationships between the western and the eastern Baltic cod stocks are presently poorly understood, the utilization of otolith microchemistry for adult and juvenile fish may be helpful as a management tool for quantifying the importance of east-westward-oriented migrations. This could be particularly useful for investigating the mixing of the 2 Baltic cod stocks, especially in ICES-Subdivision 24, a topic which is presently still under debate.

Acknowledgements. Thanks go to all people involved in sampling and storing the analyzed material. Preparation of otoliths was possible with the kind help of Dr. C. Stransky and F. Beussel at the vTI Institute of Sea Fisheries in Hamburg. H. Anders from the Department of Geosciences at the University of Bremen was always on hand to assist during the measurements with LA-ICPMS. For solving computer and software problems during statistical analyses, S. Mees was irreplaceable at the GEOMAR in Kiel as well as Dr. N. Bergmann and Dr. C. Eizaguirre from same institute in case of statistical questions. We gratefully thank Prof. Dr. A. Geffen for valuable criticism and ideas. 


\section{LITERATURE CITED}

Andersson PS, Wasserburg GJ, Ingri J (1992) The sources and transport of $\mathrm{Sr}$ and $\mathrm{Nd}$ isotopes in the Baltic Sea. Earth Planet Sci Lett 113:459-472

Bagge O, Steffensen E (1989) Stock identification of demersal fish in the Baltic. Rapp P-V Reùn Cons Int Explor Mer 190:3-16

Bagge O, Tiews K, Lamp L, Otterlind G (1974) German, Swedish and Danish cod tagging experiments in the Baltic 1968-69. Rapp P-V Reùn Cons Int Explor Mer 166: 22-39

Bagge O, Thurow F, Steffensen E, Bay J (1994) The Baltic cod. Dana 10:1-28

Baranova T (1989) Some parameters of the eastern Baltic cod population in Subdivision 26 and 28: growth and ripening in connection with abundance dynamics. Rapp P-V Reùn Cons Int Explor Mer 190:97-101

Baranova T (1995) The structure of spawning cod stock in the eastern Baltic during 1972-1995. ICES CM J:9

Begg GA, Cappo M, Cameron DS, Boyle S, Sellin MJ (1998) Stock discrimination of school mackerel, Scomberomorus queenslandicus, and spotted mackerel, Scomberomorus munroi, in coastal waters of eastern Australia by analysis of minor and trace elements in whole otoliths. Fish Bull 96:653-666

Berner M, Vaske B (1985) Morphometric and meristic characters of cod stocks in the Baltic Sea. ICES CM J:11

BLMP (2002) Meeresumwelt 1997-1998. Bundesamt für Seeschifffahrt und Hydrographie (BSH), Hamburg und Rostock

Campana SE, Chouinard GA, Hanson JM, Frechet A, Brattey J (2000) Otolith elemental fingerprints as biological tracers of fish stocks. Fish Res 46:343-357

Clarke KR, Gorley RN (2001) Primer v5: user manual/tutorial. Primer-E, Plymouth

de Vries MC, Gillanders BM, Elsdon TS (2005) Facilitation of barium uptake into fish otoliths: influence of strontium concentration and salinity. Geochim Cosmochim Acta 69: 4061-4072

Edmonds JM, Moran MJ, Caputi N, Morita M (1989) Trace element analysis of fish sagittae as an aid to stock identification: pink snapper (Chrysophrys auratus) in western Australian waters. Can J Fish Aquat Sci 46:50-54

Edmonds JS, Caputi N, Morita M (1991) Stock discrimination by trace-element analysis of otoliths of orange roughy (Hoplostethus atlanticus), a deep-water marine teleost. Aust J Mar Freshw Res 42:383-389

Eero M, MacKenzie BR, Köster FW, Gislason H (2011) Multidecadal responses of a cod (Gadus morhua) population to human-induced trophic changes, fishing, and climate. Ecol Appl 21:214-226

Fowler AJ, Campana SE, Jones CM, Thorrold SR (1995) Experimental assessment of the effect of temperature and salinity on elemental composition of otoliths using solution-based ICPMS. Can J Fish Aquat Sci 52: 1421-1430

Gillanders BM, Kingsford MJ (2000) Elemental fingerprints of otoliths of fish may distinguish estuarine 'nursery' habitats. Mar Ecol Prog Ser 201:273-286

> Higgins RM, Danilowicz BS, Balbuena JA, Daníelsdóttir AK and others (2010) Multi-disciplinary fingerprints reveal the harvest location of cod Gadus morhua in the northeast Atlantic. Mar Ecol Prog Ser 404:197-206

Hüssy K (2011) Review of western Baltic cod (Gadus morhua) recruitment dynamics. ICES J Mar Sci 68: 1459-1471

Jochum KP, Weis U, Stoll B, Kuzmin D and others (2011) Determination of reference values for NIST SRM 610-617 glasses following ISO guidelines. Geostand Geoanal Res 35:1-33

Kalish JM (1989) Otolith microchemistry: validation of the effects of physiology, age and environment on otolith composition. J Exp Mar Biol Ecol 132:151-178

> Köster FW, Möllmann C, Hinrichsen HH, Wieland $\mathrm{K}$ and others (2005) Baltic cod recruitment - the impact of climate variability on key processes. ICES J Mar Sci 62: 1408-1425

> Limburg KE, Høie H, Dale DS (2010) Bromine patterns in Norwegian coastal Cod otoliths - a possible marker for distinguishing stocks? Environ Biol Fishes 89: $427-432$

- MacKenzie B, Hinrichsen HH, Plikshs M, Wieland K, Zezera AS (2000) Quantifying environmental heterogeneity: habitat size necessary for successful development of cod Gadus morhua eggs in the Baltic Sea. Mar Ecol Prog Ser 193:143-156

> Maksymowska D, Richard P, Piekarek-Jankowska H, Riera $P$ (2000) Chemical and isotopic composition of the organic matter sources in the Gulf of Gdansk (Southern Baltic Sea). Estuar Coast Shelf Sci 51:585-598

Müller H (2002) The distribution of 'Belt Sea cod' and 'Baltic cod' in the Baltic Sea from 1995 to 2001 estimated by discriminant analysis of the number of dorsal fin rays. ICES CM L:16

Nielsen EE, Hansen MM, Ruzzante DE, Meldrup D, Grønkjær P (2003) Evidence of a hybrid-zone in Atlantic cod (Gadus morhua) in the Baltic and the Danish Belt Sea revealed by individual admixture analysis. Mol Ecol 12: 1497-1508

> Nissling A, Kryvi H, Vallin L (1994) Variation in egg buoyancy of Baltic cod Gadus morhua and its implications for egg survival in prevailing conditions in the Baltic Sea. Mar Ecol Prog Ser 110:67-74

> Otterlind G (1985) Cod migration and transplantation experiments in the Baltic. J Appl Ichthyology 1:3-16

Pearce NJG, Perkins WT, Westgate JA, Gorton MP, Jackson SE, Neal CL, Chenery SP (1997) A compilation of new and published major and trace element data for NIST SRM 610 and NIST SRM 612 glass reference materials. Geostand Newsl 21:115-144

Pohl C, Hennings U, Koßurok B (1999): Ostsee-Monitoring; Die Schwermetall-Situation in der Ostsee im Jahre 1998. Institut für Ostseeforschung Warnemünde, Universität Rostock, Rostock

> Secor DH, Rooker JR (2000) Is otolith strontium a useful scalar of life-cycles in estuarine fishes? Fish Res 46: 359-371

Secor DH, Henderson-Arzapalo A, Piccoli PM (1995) Can otolith microchemistry chart patterns of migration and habitat utilization in anadromous fishes? J Exp Mar Biol Ecol 192:15-33

Svedäng $\mathrm{H}$, André C, Jonsson $\mathrm{P}$, Elfman M, Limburg KE (2010) Migratory behaviour and otolith chemistry suggest fine-scale sub-population structure within a genetically homogenous Atlantic Cod population. Environ Biol Fishes 89:383-397

Thresher RE, Proctor CH, Gunn JS, Harrowfield IR (1994) An evaluation of electron probe microanalysis of otoliths for stock delineation and identification of nursery areas 
in a southern temperate groundfish, Nemadactylus macropterus (Cheilodactylidae). Fish Bull 92:817-840

Wachniew P (2006) Isotopic composition of dissolved inorganic carbon in a large polluted river: the Vistula,

Editorial responsibility: Hans Heinrich Janssen, Oldendorf/Luhe, Germany
Poland. Chem Geol 233:293-308

Yoshinaga J, Nakama A, Morita M, Edmonds JS (2000) Fish otolith reference material for quality assurance of chemical analyses. Mar Chem 69:91-97

Submitted: February 2, 2012; Accepted: July 4, 2012

Proofs received from author(s): September 24, 2012 